\title{
Mechanical Properties of Engineered Cementitious Composite Materials Using Different Types of Fibers
}

\author{
Mohamed A. Saafan ${ }^{1}$, Zeinab A. Etman ${ }^{1 *}$ and Samar A. Rokbah ${ }^{2^{*}}$ \\ ${ }^{I}$ Department of Civil Eng, Faculty of Eng., Menoufia University, Egypt \\ "Higher Institute of Engineering. and Technology, Menoufia \\ ${ }^{2}$ PhD Candidate, Depart. of Civil Eng., Faculty of Eng., Menoufia University, Egypt
}

\begin{abstract}
An Engineered Cementitious composite is an ultra-ductile cementitious composite that is highly crack resistant, with a tensile strain capacity over that of normal concrete. In this study, three different types of PolyPropylene. fibers are added to cement mortars to determine how they can be used to develop Engineered Cementitious Composites materials. Fibers are used in different (aspect ratios, tensile strengths, and different proportions in volume fraction $(1.0,2.0,3.0$, and $4.0 \%)$ in concrete mixture design. Hardened concrete properties, 28-days splitting tensile strength, flexural strength, cracking width were evaluated. Statistically significant effects were observed for polypropylene fibers on the splitting tensile and flexural strength, toughness indexes, and durability parameters showed an increase in the presence of polypropylene fibers. Increased fiber availability (fiber aspect ratio) in the concrete matrix, in addition to the ability of longer polypropylene fibers to bridge the micro cracks, are suggested as the reasons for the enhancement in mechanical properties. Finally, crack width in fiber-reinforced concrete is affected with fiber property variables (fiber type, length, diameter, and proportion). The experimental results showed that with an increase in fiber length and/or decrease in fiber diameter crack width, decrease significantly.
\end{abstract}

Keywords: Polypropylene Fiber; Flexure; Crack width; ductility index;

\section{Introduction}

Advanced composite material is represented by engineered cementitious composite materials (ECC), which demonstrate a pseudo-strain hardening response in tension. The substance consists of a Portland cement paste or mortar matrix with a low volume fraction of fibers such as polyethylene ultra-high molecular weight (UHMWPE) or polyvinyl alcohol (PVA) fibers. The remarkable advantage is its ability to demonstrate multiple cracking in tension, which in contrast to the brittle behavior of conventional cementitious materials offers considerable tensile strain power. Continued development of the materials will give engineers greater flexibility to design and rehabilitate structures to withstand seismic and other types of loading. ECC materials are part of a larger class of materials, fiber reinforced concrete (FRC)[1].

FRC properties, such as crack resistance, reinforcement, and increase in toughness are dependent on the mechanical properties of the fiber, bonding properties of the fiber and matrix, as well as the quantity and distribution within the matrix of the fibers[2,3]. Concerning the elastic modulus, the fibers are classified into two types, those that the elastic modulus of fibers is less than the elastic modulus of the matrix (i.e. cellulose fiber, polypropylene (PP) fiber, polyacrylonitrile
(PAN) fiber, etc.), and those that the elastic modulus of fibers is greater than the elastic modulus of the matrix (i.e. asbestos fibers, glass fiber, steel fiber, carbon fiber, aramid fiber, etc.).

Polypropylene fibers have advantageous characteristics; due to their smooth surface and chemical inertness, the weak bond with the cement matrix remains a significant drawback. The fibermatrix bond has been shown to strongly influence fibers' ability to stabilize crack propagation in the matrix. As this bond between fiber and matrix is mainly mechanical, the incorporation of fly ash into fiber-reinforced cement composites seems to provide better matrix bonding through porous refinement and better distribution of hydration products [4]. Lee Siong[5] observed that using local ingredients such as P.P. fiber in Malaysia, the increase in fiber content does not have a major impact on the enhancement of ECC mechanical properties based on ECC efficiency in both tensile and compressive properties. Therefore, $1.5-2.0 \%$ of fibers in volume fraction are sufficient in this series of ECC mixes. Bang Yeon Lee[6], discussed the Composite efficiency combined with P.P. Fiber.

Amount of P.P. fiber was used $2 \%$ volume fraction. Polystyrene beads have also been used to improve composite tensile ductility; these beads have a very poor bond with a cementitious matrix, and they serve as an artificial defect under tensile 
testing. The test results showed that high tensile strain capacities (3\% to $6 \%$ ) can be attained by employing high-strength P.P fibers in cementitious composites. Sallal R. Abid[7] was investigated three main mechanical properties, which were the compressive strength, the splitting tensile strength, and the flexural strength of engineered cementitious composites incorporating P.P. fibers with five different doses of $0,0.5,1.0,1.5$, and $2.0 \%$. The test results showed that the percentage of fiber has a significant impact on the tensile strength, where both the splitting tensile strength and the modulus of rupture were increased with the increase of fiber content. Oppositely, the effect of fiber content on the compressive strength was insignificant. Wei Zhang[8] was studied the mechanical properties and carbonation durability of engineered cementitious composites (ECC). For the cost-efficient utilization of ECC materials, different types of specimens were cast with polypropylene (PP) and hydrophilic polyvinyl alcohol (HPVA) fibers. Two types of ECC materials with different fiber contents of $0 \mathrm{vol} \%, 1 \mathrm{vol} \%, 1.5 \mathrm{vol} \%$, and 2 $\%$ volume fraction, were investigated with the use of compressive tests, four-point bending tests, drop-weight tests, and uniaxial tensile tests. The results indicated that for both P.P fiber- and HPVA fiber-reinforced ECCs, the compressive strength first increases and then decreases as fiber content increases from 0 vol. $\%$ to 2 vol. $\%$, reaching a maximum at 1 vol. \% fiber content. The bending strength, deformation capacity, and impact resistance show significant improvement with increasing fiber content. The ECC material reinforced with 2 vol. \% PP fiber shows superior carbonized durability with a maximum carbonation depth of only $0.8 \mathrm{~mm}$. Also, the mechanical properties of ECC Ali Raza Khoso[9] were studied with addition of Polypropylene fiber at different percentages $0 \%, 0.25 \%, 0.5 \%, 0.75 \%, 1.0 \%$. The experimental results showed that $111.4 \%$ increment in tensile strength was found at $0.5 \%$ PP fiber at ECC $1: 1: 1$ and an improvement of $74.74 \%$ were observed at ECC 1:0.8:1.2 at 1\% PP fiber. The study concludes that this composite can replace the normal concrete where high tension is the ultimate requirement with higher strain capacity. Rathod JD[10] Studied the effect of single fiber pull-out test results on flexural performance of Engineered Cementitious Composite (ECC). P.P. fiber with a ratio of $4.0 \%$ and Cement: sand ratios of $1: 0.5,1: 1$, $1: 1.5$, and $1: 2$ are used in the composition of ECC. Experimental results demonstrate the unique and stunning performance of ECC in flexure, not seen before in any cementitious composites. In addition, the flexural performance of ECC, however, reduces with the increase in sand content. ECC absorbs large energy by the inelastic deformation mechanism. Cement: sand ratio of $1: 0.5$ is suggested for optimum performance.

\section{Research Significants}

This paper describes the results of an experimental investigation studying the effect of different fibers types and percentages on flexure and tensile strength on the flexural and tensile properties as well as crack development characteristics of ECC mixtures. Overall, the recommendations of this paper will be beneficial to engineers, designers and local industries engaged in manufacturing and using cost-effective and greener ECC mixtures for construction applications.

\section{Experimental Program}

To utilize the experimental work, twelve mixes were prepared from ECC. A series of ECC mortar mixes with a ratio of sand/cement equal to 0.8 and a fly ash/cement ratio equal to $50 \%$ was designed and tested. Polypropylene fibers were used with different volume fractions of $(1.0,2.0,3.0$, and 4.0 $\%$ ). A total of 36 prisms $25 \times 100 \times 300[10] \mathrm{mm}$ were cast and tested to determine the flexural behavior of hardened concrete. A total of $36 \mathrm{dog}$ bones $10 \times 100 \times 300 \mathrm{~mm}$ were tested to determine the tensile strength of the mixes at 28 days.

\subsection{Materials}

\section{Cement}

Portland cement (CEM I $42.5 \mathrm{~N}$ ) conformed to the requirements of (E.S.S.4756-1/2013)[11] with a specific gravity of 3.16 and Blain fineness of 3980 $\mathrm{cm}^{2} / \mathrm{gm}$. and (E.P.C 203/2018)[12].

\section{Sand}

Well graded siliceous sand conformed to the requirements of (E.S.S.1109/2008)[13] with a specific gravity of 2.60 , absorption of $0.81 \%$, and a fineness modulus of 2.55 and (E.P.C 203/2018)[12].

Fly Ash

Class (F) fly ash meeting the requirements of (ASTM C618)[14] with a specific gravity of 2.1 was used.

\section{Water}

Water per binder (fly ash+ cement) ratio $(\mathrm{w} / \mathrm{b})$ was 0.22 . Tap water was used for mixing the concrete conformed to the requirements of (E.P.C 203/2018)[12].

\section{Admixture}

A high range water reducer (HRWR) was used as a superplasticizer meeting the requirements of (ASTM C494 type A and F)[15]. The admixture is a brown liquid having a density of $1.18 \mathrm{~kg} /$ liter at room temperature. The dosage of HRWR was $0.5 \%$ of the powder (fly ash + cement) weight.

\section{Polypropylene Fiber}

Three types of Poly Propylene fibers were used. The fibers accounted for the total mix volume. 
Mohamed Saafan, Zeinab Etman, Samar Rokba "Mechanical Properties of Engineered ... "

Table 1- Property of Poly Propylene Fiber Used

\begin{tabular}{ccccccc}
\hline Type of Fiber & $\begin{array}{c}\text { Length } \\
\text { range }(\mathrm{mm})\end{array}$ & $\begin{array}{c}\text { Average } \\
\text { diameter } \\
(\mu \mathrm{m})\end{array}$ & $\begin{array}{c}\text { Aspect } \\
\text { ratio } \\
(\mathrm{L} / \mathrm{d})\end{array}$ & $\begin{array}{c}\text { Tensile } \\
\text { Strength } \\
(\mathrm{MPa})\end{array}$ & $\begin{array}{c}\text { Fiber } \\
\text { elongation } \\
(\%)\end{array}$ & $\begin{array}{c}\text { Specific } \\
\text { gravity } \\
\left(\mathrm{kg} / \mathrm{m}^{3}\right)\end{array}$ \\
\cline { 1 - 5 }$(\mathrm{TC})$ & $(12-20)$ & 20 & 800 & $550-600$ & $14-25 \%$ & \multirow{2}{*}{0.9} \\
\cline { 1 - 5 }$(\mathrm{SF})$ & $(3-18)$ & 18 & 583 & $300-400$ & $>80 \%$ & \\
\cline { 1 - 5 } & $(6,12,20)$ & 34 & 471 & $500-700$ & $20 \%$ & \\
\hline
\end{tabular}

TC: Tri Concrete[16] SF: Sika Fiber ${ }^{\circledR}[17] \quad$ FM: Fiber mesh ${ }^{\circledR 300-e 3[18] ~}$

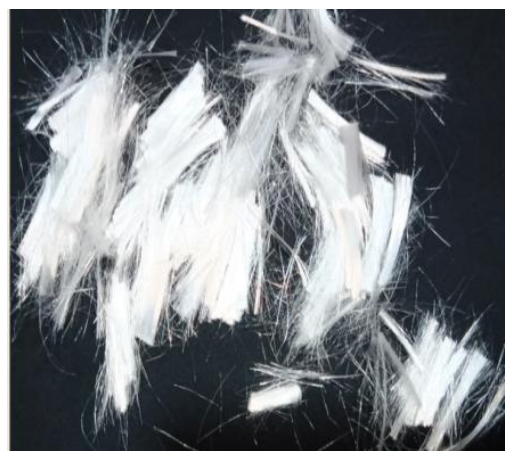

Tri Concrete Fiber

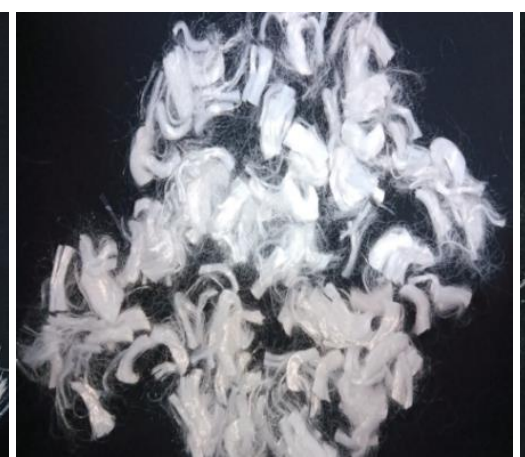

Sika Fiber ${ }^{\circledR}$

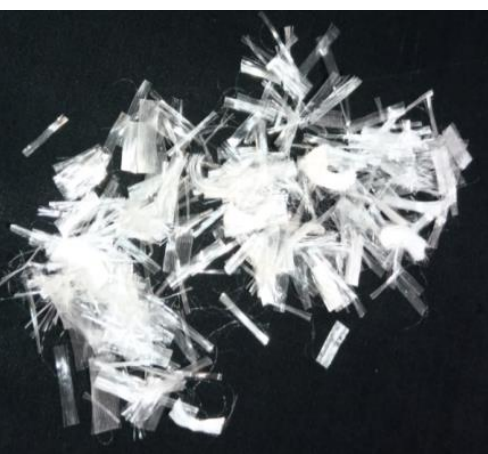

Fiber mesh ${ }^{\circledR} 300$-e3

Figure 1- Polypropylene fibers used.

\subsection{Mixing, Casting, and Testing Procedures}

To prepare the ECC mixes; an electrical mixer with 15 liters capacity was used. Fine sand, cement and fly ash were first mixed for one minute until the mixture becomes homogeneous. Water and HRWR were added into the dry mixture and mixing continued for 3 minutes. It is important to ensure that consistency and homogeneity of the fresh mortar before adding the fibers.

Polypropylene fibers were added slowly and mixing continued for 2 to 3 minutes to ensure that the fibers were equally distributed. The fiber is surface-coated by oil to minimize the fiber/matrix interfacial bond strength. The mixtures were cast in one layer then vibrated using vibrating table.

The specimens were remolded after 24 hours and then cured in water (the ambient conditions in the laboratory: the temperature $=20 \stackrel{\circ}{ } \mathrm{C}$ and the relative humidity $=45 \pm 5 \%$ ) until the date of the testing. The Mixes features are reported in Table (2).

Table 2- Constituents of concrete mixes $\left(\mathrm{kg} / \mathrm{m}^{3}\right)$.

\begin{tabular}{cccccccc}
\hline $\begin{array}{c}\text { Fiber } \\
\text { Type }\end{array}$ & $\begin{array}{c}\mathrm{Mix} \\
\mathrm{No}\end{array}$ & $\begin{array}{c}\text { Cement } \\
\left(\mathrm{kg} / \mathrm{m}^{3}\right)\end{array}$ & $\begin{array}{c}\text { Sand } \\
\left(\mathrm{kg} / \mathrm{m}^{3}\right)\end{array}$ & $\begin{array}{c}\text { Water } \\
\left(\mathrm{kg} / \mathrm{m}^{3}\right)\end{array}$ & $\begin{array}{c}\text { Fly ash } \\
(\mathrm{kg} / \mathrm{m})\end{array}$ & $\begin{array}{c}\text { Poly Propylene } \\
(\text { PP) (Fiber) } \\
\left(\mathrm{kg} / \mathrm{m}^{3}\right)\end{array}$ & $\begin{array}{c}\text { HRWRA } \\
\left(\mathrm{kg} / \mathrm{m}^{3}\right)\end{array}$ \\
\hline-- & $\mathrm{C}$ & 671.14 & 536.91 & 295.30 & 671.14 & - & 6.71 \\
& & & & & & & \\
\hline $\mathrm{TC}$ & $\mathrm{TC}_{1}$ & 664.43 & 531.54 & 292.35 & 664.43 & $9.0(1.0 \%)^{*}$ & 6.64 \\
& $\mathrm{TC}_{2}$ & 657.72 & 526.18 & 289.39 & 657.72 & $18.0(2.0 \%)^{*}$ & 6.58 \\
& $\mathrm{TC}_{3}$ & 651.0 & 520.80 & 286.44 & 651.0 & $27.0(3.0 \%)^{*}$ & 6.51 \\
& $\mathrm{TC}_{4}$ & 644.30 & 515.44 & 283.49 & 644.30 & $36.0(4.0 \%)^{*}$ & 6.44 \\
\hline $\mathrm{SF}$ & $\mathrm{SF}_{1}$ & 664.43 & 531.54 & 292.35 & 664.43 & $9.0(1.0 \%)^{*}$ & 6.64 \\
& $\mathrm{SF}_{2}$ & 657.72 & 526.18 & 289.39 & 657.72 & $18.0(2.0 \%)^{*}$ & 6.58 \\
& $\mathrm{SF}_{3}$ & 651.0 & 520.80 & 286.44 & 651.0 & $27.0(3.0 \%)^{*}$ & 6.51 \\
& $\mathrm{SF}_{4}$ & 644.30 & 515.44 & 283.49 & 644.30 & $36.0(4.0 \%)^{*}$ & 6.44 \\
\hline $\mathrm{FM}$ & $\mathrm{FM}_{1}$ & 664.43 & 531.54 & 292.35 & 664.43 & $9.0(1.0 \%)^{*}$ & 6.64 \\
& $\mathrm{FM}_{2}$ & 657.72 & 526.18 & 289.39 & 657.72 & $18.0(2.0 \%)^{*}$ & 6.58 \\
& $\mathrm{FM}_{3}$ & 651.0 & 520.80 & 286.44 & 651.0 & $27.0(3.0 \%)^{*}$ & 6.51 \\
& $\mathrm{FM}_{4}$ & 644.30 & 515.44 & 283.49 & 644.30 & $36.0(4.0 \%)^{*}$ & 6.44 \\
\hline
\end{tabular}

*): Fiber volume fraction 


\subsection{Mechanical Tests Flexural strength}

This test method evaluates the flexural strength obtained by testing simply supported beam (prism)

The load was applied without shock. The load increased until the specimen fails and the maximum load applied to the specimen during the test shall be recorded. The flexural strength of the specimen was calculated as follows:

Flexural strength $\mathrm{F}_{f}(\mathrm{MPa})=\frac{M}{I} \times y$

Figure (3) shows a universal testing machine with $30 \mathrm{KN}$ was used to obtain the flexural strength of tested specimens

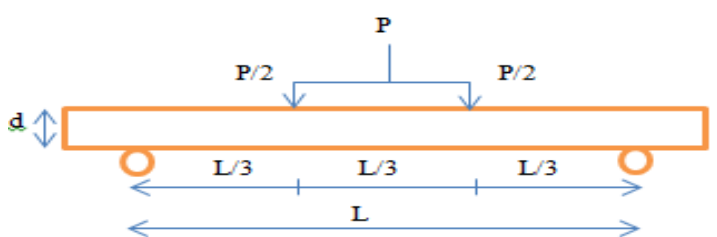

Figure 2- Four Point Loading Set UP

\section{Tensile Strength}

This test was carried out to determine the tensile strength of specimens of concrete dog bones after 28 days. This test method consists of applying a tensile axial load to molded dog bone until failure occurred. The tensile strength of the specimen was calculated by dividing the maximum load attained during the test by the cross-sectional area of the specimen, which in the research was $2000 \mathrm{~mm}^{2}$. Figure (3) shows the universal testing machine with a capacity of $30 \mathrm{KN}$, which used to obtain the flexural and tensile strength of tested specimen under four-point loading at universal testing machine as shown in Figure (2). The specimens were supported on roller with $200 \mathrm{~mm}$ span for $(300 * 100 * 25 \mathrm{~mm})$ size specimen.

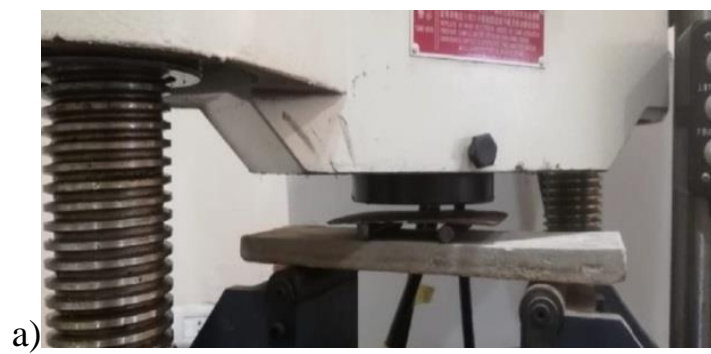

b)

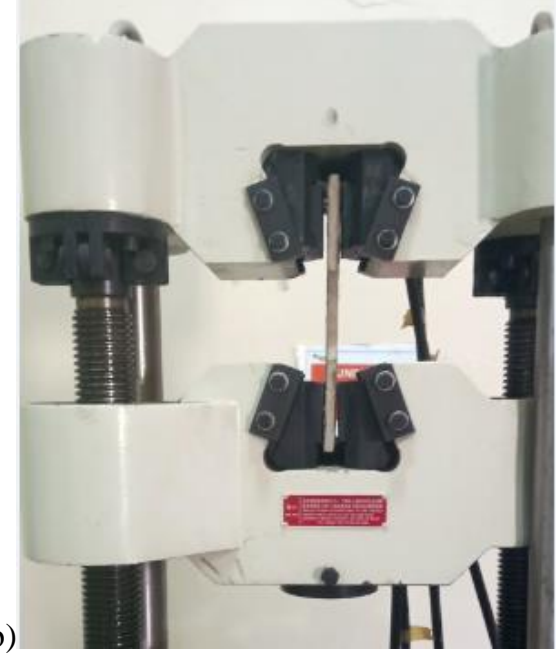

Fig. 3- Universal Testing Machine For a) Flexural Loads and b) Tensile Loads

Table 3- Flexural and Tensile strength of ECC mixtures

\begin{tabular}{|c|c|c|c|c|c|c|c|c|c|c|c|}
\hline $\begin{array}{l}\text { Fiber } \\
\text { Type }\end{array}$ & Mix & $\begin{array}{l}\mathrm{V}_{f} \\
(\%)\end{array}$ & $\begin{array}{l}\text { Ultimate } \\
\text { Load }\end{array}$ & $\begin{array}{r}\mathrm{F}_{f} \\
\mathrm{MPa}\end{array}$ & $\begin{array}{c}\text { Max } \\
\text { deflection } \\
(\mathrm{mm})\end{array}$ & $\Delta \mathrm{u}$ & $\Delta y$ & $\begin{array}{c}\text { Duct } \\
\text { ility } \\
\text { Inde } \\
x\end{array}$ & $\begin{array}{l}\text { Tensile } \\
\text { strengt } \\
\text { h } \mathrm{MPa}\end{array}$ & $\begin{array}{c}\text { Strai } \\
\mathrm{n} \text { at } \\
\text { fatigu } \\
\mathrm{e}\end{array}$ & $\begin{array}{c}\text { Tough } \\
\text { ness } \\
\text { Index }\end{array}$ \\
\hline-- & $\mathrm{C}$ & 0.0 & 4.95 & 37.12 & 1.5 & 1.5 & 1.5 & 1.0 & 2.50 & 0.10 & 0.33 \\
\hline \multirow{4}{*}{$\mathrm{TC}$} & $\mathrm{TC}_{1}$ & 1.0 & 5.25 & 39.37 & 20 & 5 & 1.0 & 5.0 & 4.68 & 1.0 & 11.44 \\
\hline & $\mathrm{TC}_{2}$ & 2.0 & 6.24 & 47.02 & 20 & 16 & 0.70 & 22.85 & 5.08 & 1.33 & 25.58 \\
\hline & $\mathrm{TC}_{3}$ & 3.0 & 7.70 & 57.75 & 30 & 24 & 0.40 & 60 & 6.36 & 1.67 & 28.27 \\
\hline & $\mathrm{TC}_{4}$ & 4.0 & 8.91 & 66.82 & 22 & 10 & 0.40 & 25 & 6.13 & 1.66 & 23.16 \\
\hline \multirow{4}{*}{ SF } & $\mathrm{SF}_{1}$ & 1.0 & 5.25 & 39.37 & 15 & 5 & 1.07 & 4.67 & 4.80 & 1.67 & 8.32 \\
\hline & $\mathrm{SF}_{2}$ & 2.0 & 6.41 & 48.07 & 16 & 7 & 0.50 & 14.0 & 5.16 & 2.33 & 13.76 \\
\hline & $\mathrm{SF}_{3}$ & 3.0 & 6.56 & 49.19 & 15.5 & 6 & 0.30 & 20.0 & 5.27 & 1.0 & 14.05 \\
\hline & $\mathrm{SF}_{4}$ & 4.0 & 5.72 & 42.89 & 16 & 6 & 0.80 & 7.5 & 5.25 & 2.0 & 13.41 \\
\hline \multirow{4}{*}{$\mathrm{FM}$} & $\mathrm{FM}_{1}$ & 1.0 & 7.35 & 55.12 & 8 & 2.17 & 0.50 & 4.34 & 4.54 & 1.0 & 5.55 \\
\hline & $\mathrm{FM}_{2}$ & 2.0 & 9.87 & 74.02 & 8.3 & 5.34 & 0.56 & 9.53 & 5.13 & 1.17 & 6.84 \\
\hline & $\mathrm{FM}_{3}$ & 3.0 & 9.87 & 74.02 & 15 & 9.8 & 0.30 & 32.67 & 5.77 & 1.33 & 11.54 \\
\hline & $\mathrm{FM}_{4}$ & 4.0 & 9.68 & 72.6 & 9.7 & 5.4 & 0.70 & 7.71 & 5.83 & 1.67 & 14.25 \\
\hline
\end{tabular}

Where: $\mathrm{F}_{f}=$ Flexural Strength

Max tensile strength at max load and Ultimate strain at max load

Toughness Indexes are calculated as a ratio of the area of the stress-strain curve 


\section{RESULTS AND DISCUSSIONS}

Different parameters were used to study the properties of ECC. The results of the experimental program are detailed in the following sections.

\subsection{Flexural Loads}

\subsubsection{Effect of Using Different Fiber Percentages}

The experimental load versus mid-span deflection curves of the three types of Polypropylene fibers at different fiber percentages involved in this program as well as their ultimate states are given in Figures (4) to (6) and Table (3). The results of all types of fiber-reinforced concrete show an appreciable increase in flexural loads and deflection compared to control mix without fibers that did not give high progress in resisting flexural loads and the failure occurred rapidly. Also, an increase in the fiber content clearly shows better performance in load and deflection.

This is due to the contribution of more fibers in flexure load before fracture of the samples by preventing the propagation of the fine cracks in the direction of the load, which makes it more efficient in delaying the growth of micro cracks and thereby improving the ultimate flexure strength capacity [19]. Although, increase of polypropylene fibers achieve an increase in load and deflection at the same load compared to control mix. For example Figure (4) shows mixes with (TC) Fiber, observed that the mixes with $4.0 \%\left(\mathrm{~V}_{f} \%\right)$ have a highest value of flexural load which are increasing by $80 \%$ more than control mix. On the other hand, the maximum deflection recorded for the mix with $3.0 \%\left(\mathrm{~V}_{f} \%\right)$ which more than control mix by $1900 \%$. AT Figure (5) for (SF) fiber the results were very closed in the ultimate load, the mix with $3.0 \%\left(\mathrm{~V}_{f} \%\right)$ was the highest increasing by $32.5 \%$ more than control mix. While the mixes with 2.0 and $4.0 \%\left(\mathrm{~V}_{f} \%\right)$ recorded the maximum deflection which increased by $966 \%$ compared to control mix. At Figure (6) for (FM) fiber the results show the ultimate load for the mix with 2.0, 3.0 \% $\left(\mathrm{V}_{f} \%\right)$ were the highest more than control mix by $99.4 \%$. In addition to, the max deflection was for the mixes with $3.0 \%\left(\mathrm{~V}_{f} \%\right)$ that increased by $900 \%$ more than control mix. From Table (3) and Figure (7) illustrate the relation between the fiber percentages $\mathrm{V}_{f} \%$ and the flexural strength. As can be seen at (TC) fiber as the fiber percentages increased the flexural strength increased, specimen containing more proportion of fiber $4 \% \mathrm{~V}_{f}$, show the maximum flexural strength. $6 \%, 27 \%, 56 \%$ and $80 \%$ increasing in the flexural strength of the mixes with 1.0, 2.0, 3.0 and $4.0 \% \mathrm{~V}_{f}$, more than control mix. The same trend were recorded for (SF) and (FM) fiber as the fiber percentages increased the flexural strength increased until reaches 3\% volume fraction then the flexural strength decreased among all fiber reinforced concretes. For $(\mathrm{SF})$ at $3.0 \%\left(\mathrm{~V}_{f}\right)$ leads to an increase in the flexural strength of about $6,31,33$ and $16 \%$ for $1.0,2.0,3.0$ and $4.0 \%$ more than control mix. Likewise, for (FM) specimens with 1.0, 2.0, 3.0 and $4.0 \%$ increasing the flexural strength of about 48.5, 99.4, 99.4 and $95.6 \%$ more than control mix.

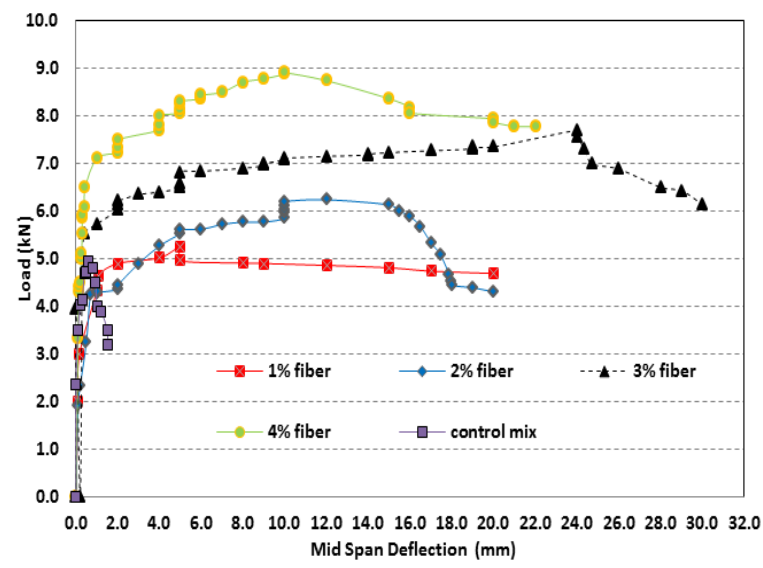

Figure 4- Mid-span relationship (tri concrete)

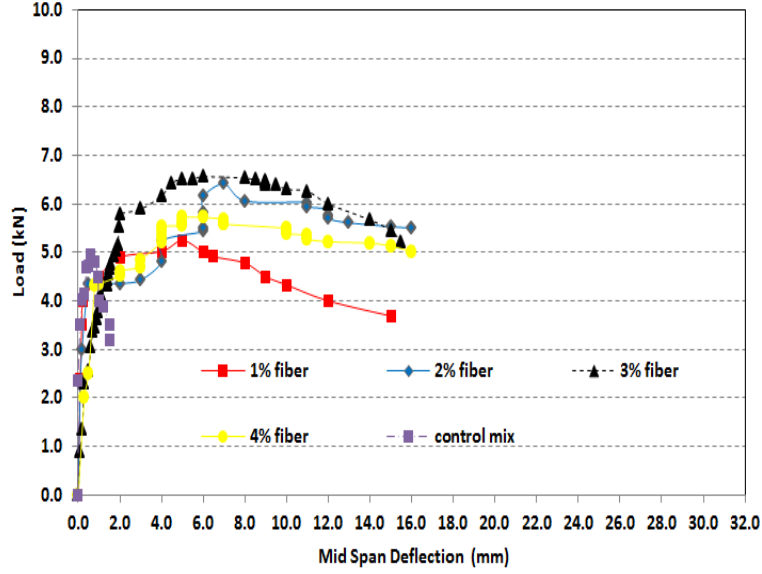

Figure 5- Mid-span relationship (Sika Fiber®) 


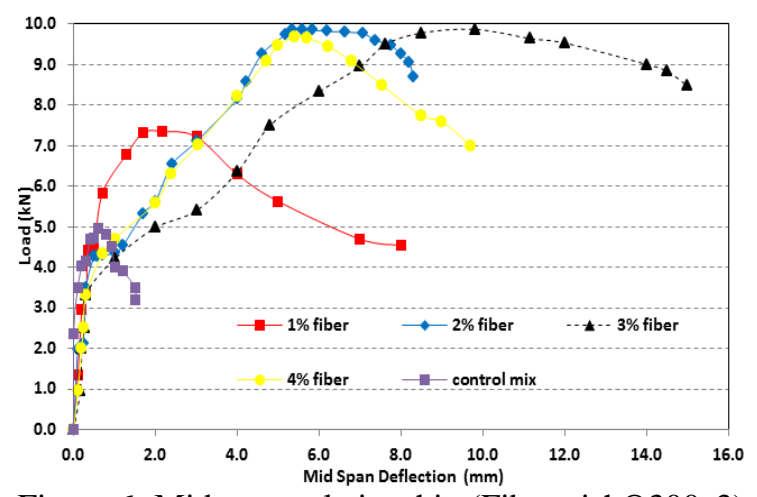

Figure 6- Mid-span relationship (Fibermish $® 300 \mathrm{e} 3$ )

\subsubsection{Effect of Using Different Fiber Types}

Figures (8) to (11) illustrate the relation between mid-span deflection and load as comparison between three types of fiber at the same ratio of volume fraction. It can be seen the addition of Polypropylene fibers have advantageous characteristics comparing to control mix. Due to the large number of micromechanical parameters governing composite response.

A new version of ECC incorporating high tenacity polypropylene fiber is developed as a result. In general, the strength and energy criteria must be considered to ensure adequate initiation of multiple cracks, and that cracks initiated propagate in the flat steady-state cracking mode, in order to achieve saturated multiple cracking so that a robust ductile composite is assured.

The micromechanical-based model can be translated into specific guidance for composite component tailoring. Parametric studies revealed that enhanced fiber strength may benefit composite ductility at high interfacial friction condition $\tau_{0}$. In contrast, increase of fiber length promotes composite multiple-cracking behavior primarily at low $\tau_{0}$ region. Where, frictional bond strength $\left(\tau_{0}\right)$ can be computed as $\mathrm{p}_{\mathrm{b}} / \pi \mathrm{d}_{\mathrm{f}} \mathrm{l}_{\mathrm{f}}[21,22,23]$. In addition to, the better bonding result of P.P fibers shall be attributed to energy dissipation and stress damping capabilities, which are important factors in fracture mechanism for increasing bonding energy at interface of adherent materials.

The energy dissipation and damping of PP fibers are related to physical properties of fiber (higher modulus of elasticity and more elongation comparing with other fibers)[24]. According to the previous researches the improvement in bond between concrete and fiber depend on high length which perform high tensile strength and elongation. From Table (1)

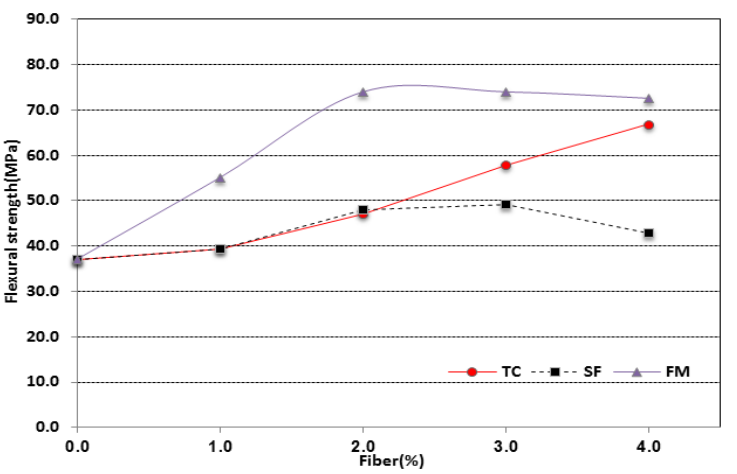

Figure 7- Effect of fiber(\%) on flexural strength

It can be noticed that tri concrete (TC) and Fibermish ${ }^{\circledR}$ 300-e3 (FM) fibers have the max value in length and strength but (TC) only has the max value in elongation. So that, in figures from 8 to 11 (FM) fiber is the highest in the ultimate load compared to the other fibers and control mix but (TC) fiber recorded the maximum deflection comparing to other fibers and control. For example at Figure (8) and from Table (3) at $1.0 \%$ volume fraction of three types of fibers and control mix. The figure shows that the ultimate load for mix with (FM) is the highest one. $48.5 \%$ increasing in the ultimate loads for the mixes with (FM) compared to control mix. On the other hand, (TC) fiber recorded the maximum value in deflection. This value is more than control mix by $1233 \%$ The same trends were recorded in Figure (9) at $2.0 \%$ volume fraction of fibers and control mix. The figure shows that the ultimate load for mix with (FM) is the highest one. These measured increased by $99.4 \%$ compared to the control mix. While (TC) fiber increased in deflection by $1233 \%$ compared to control mix. Figure (10) at $3.0 \%$ volume fraction. $99.4 \%$ increasing in the ultimate loads for the mixes with (FM) compared to control mix. While (TC) increasing in deflection by $1900 \%$ compared to control mix. Figure (11) at $4.0 \%$ volume fraction of fibers and plain concrete. These measured increased by $95.6 \%$ for the mixes with (FM) compared to control mix. While, (TC) increasing in deflection by $1367 \%$ compared to control mix Also, from Figure (7) above it can be observed that specimen containing of the (FM) is the highest in the flexural strength followed by (TC) specimen with then finally by specimen with (SF). For example, at $3 \%$ volume fraction the flexural strength is $57.75,49.19,74.02$ for (TC), (SF) and (FM), respectively. 


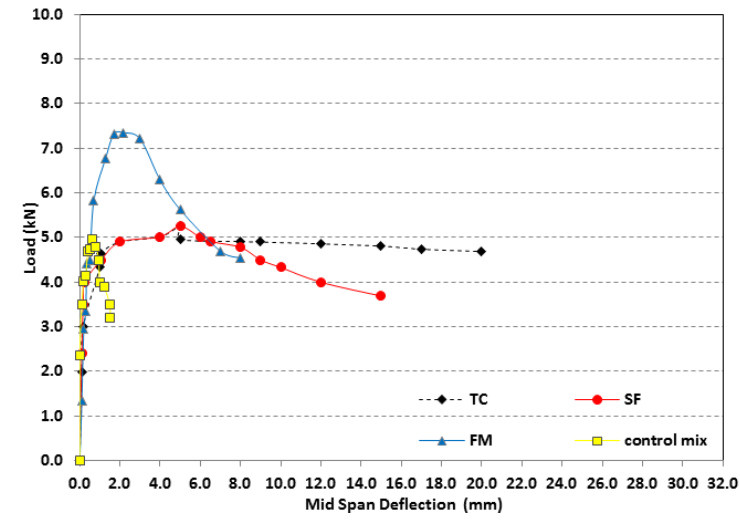

Figure 8- The relation between mid-span deflection

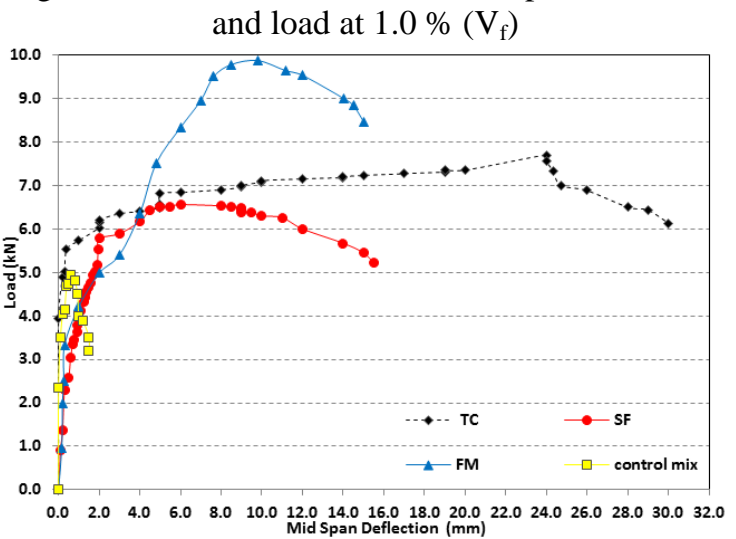

Figure 10- The relation between mid-span deflection and load at $3.0 \%\left(\mathrm{~V}_{\mathrm{f}}\right)$.

\subsubsection{Deformability and Ductility index}

In limit and seismic design the ductility of a member is usually expressed as the ratio of the ultimate deformation to the deformation at first yield. Member ductility can be expressed in terms of deflection. ACI defined a deflection ductility index $(D i)$ as following:

$$
D i=\frac{\Delta u}{\Delta y}
$$

Where: $D_{i}$ is deflection ductility index.

$\Delta u$ is the final deflection corresponding tomax load.

$\Delta y$ is the member deflection at first yielding of the tension reinforcement.

From Table (3) by comparing all mixtures with fiber and without fiber (control mix), the results show the use of fiber increased the ductility index of the mixes compared to control mix that did not give progress in resisting flexural loads and the failure occurred rapidly without any progress in ductility index. For the same type of fiber at Figure (12), generally the ductility index was increased by increased the percentage of volume fraction until reached $3.0 \%$ volume fraction then decreased. For example at (TC) group, the ductility index were $5.0,22.85,60$ and 25 for $1.0 \%, 2.0 \%, 3.0 \%$ and $4.0 \%\left(\mathrm{~V}_{f} \%\right)$, respectively. For (SF) group, the ductility index were 4.67, 14, 20 and 7.50 for 1.0 $\%, 2.0 \%, 3.0 \%$ and $4.0 \%\left(\mathrm{~V}_{f} \%\right)$, respectively. For

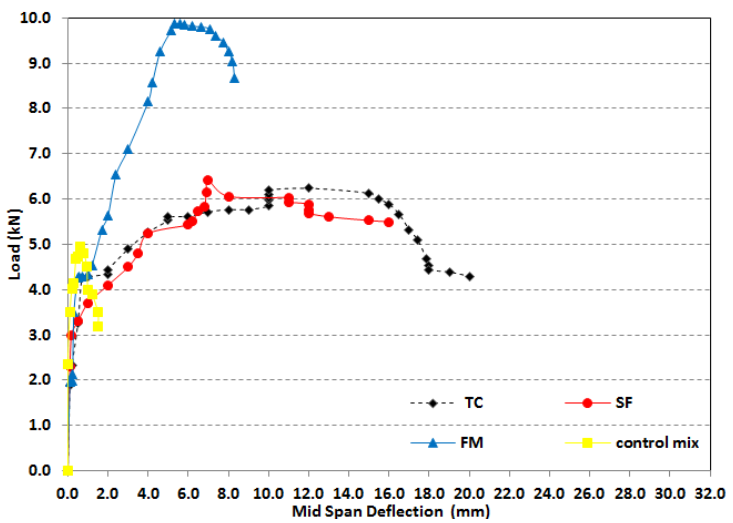

Figure 9- The relation between mid-span deflection and load at $2.0 \%\left(\mathrm{~V}_{\mathrm{f}}\right)$.

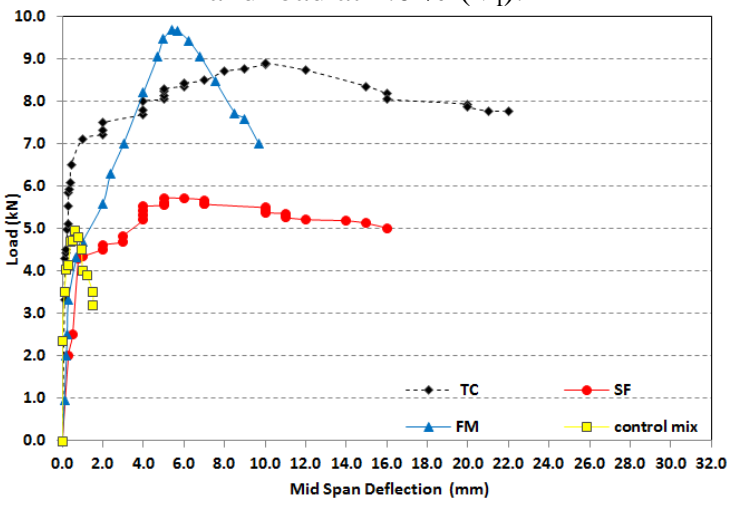

Figure 11- The relation between mid-span deflection and load at $4.0 \%\left(\mathrm{~V}_{\mathrm{f}}\right)$.

(FM) The ductility index were 4.34, 9.53, 32.67, and 7.71 for $1.0 \%, 2.0 \%, 3.0 \%$ and $4.0 \%\left(\mathrm{~V}_{f} \%\right)$, respectively.

As comparing all fibers together, the results show that the specimens with (TC) fiber gave the max ductility index at all percentages of fibers this is due to the fiber was the highest in length, strength, and elongation as can be seen in Table (1) and has mentioned above. For example, at $3.0 \%$ $\left(\mathrm{V}_{f} \%\right)$ which recorded the maximum value in all percentages of fiber volume fraction. The ductility index of the mix with (TC) is more than that of the mix with (SF), (FM) by $200,83.65 \%$.

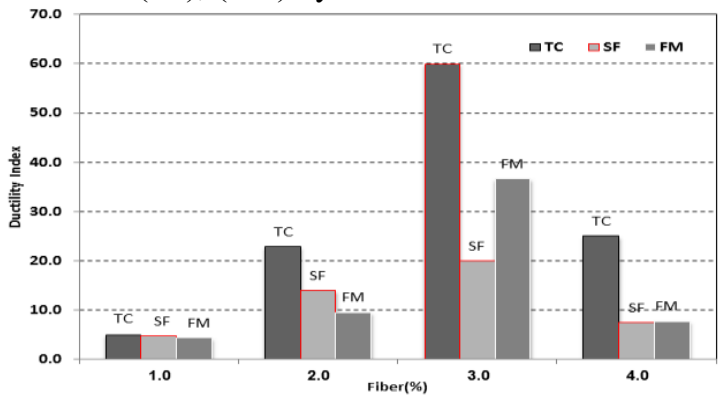

Figure 12- Effect of fiber (\%) and type on ductility index 


\subsubsection{Effect of fiber types on the crack width of ECC}

The function of the polypropylene fiber mixed into concrete is to avoid the creation of microcracks in the concrete thus imparting ductility to it. Polypropylene fibers are used in concrete is to obtain a much better, and more stable surface and also a more surface resistant piece of concrete[25]. When a crack is formed in ECC it prevents fibers that bridge the crack from opening up more. With the shrinkage action, fibers transmit forces through the crack, thus creating tensile stresses along the ring. If fiber transmitted loads are very small, as composites containing very low fiber volumes, the second crack will not occur because the tensile stress is transmitted across the crack is lower than the matrix's tensile strength. When the proportioning of fibers is increased, more cracks develop with a smaller width.

Experimental findings support the pattern [26]. Figure (13) shows the relation between the crack width and the different percentages of volume fraction for (TC), (SF), and (FM) fiber of specimens under flexural load. The evolution of cracking with time issued from images analysis for samples, the results showed that the widest crack width and the total crack width decrease when fibers are added to specimens. This is evident in all types of fibers when fibers are added to specimens, it can be concluded by increasing the volume fraction of the fiber in the concrete mixture, crack width decreases, which could be affected by a greater fiber bridge effect in the concrete matrix.
For example, at (TC) fibers the minimum crack width at $3 \%$ as shown in Figure (14). The same recorded at (FM) and (SF) fibers the minimum crack width at $3 \%$ and $4 \%$ as shown in Figure (15) and (16). In addition, one of the more important properties of concrete fiber is the aspect ratio. It is well documented that fibers in concrete have a bridge effect and are very sensitive to the size of the material used in the mixed design. In Table (1), in the case of (TC) and (SF), it can be concluded that increases in the aspect ratio of the fibers Table (1) significantly contribute to reducing the crack width for experimental results. This because with an increase in the aspect ratio of fibers, the specific area of the fibers increases, and consequently mechanical entanglement fibers in the concrete increased [27].

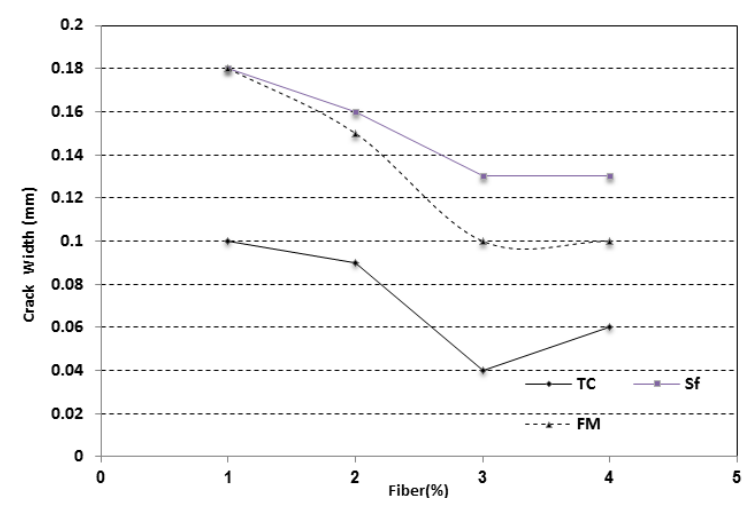

Figure 13-Effect of fiber $(\%)$ on crack width under flexural test
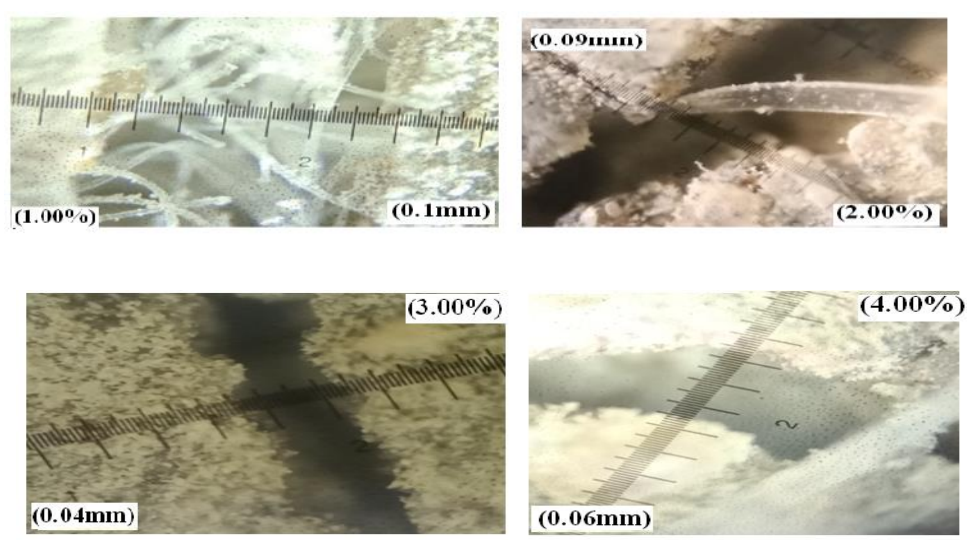

Figure 14- Crack width during the flexural test for tri concrete fiber 

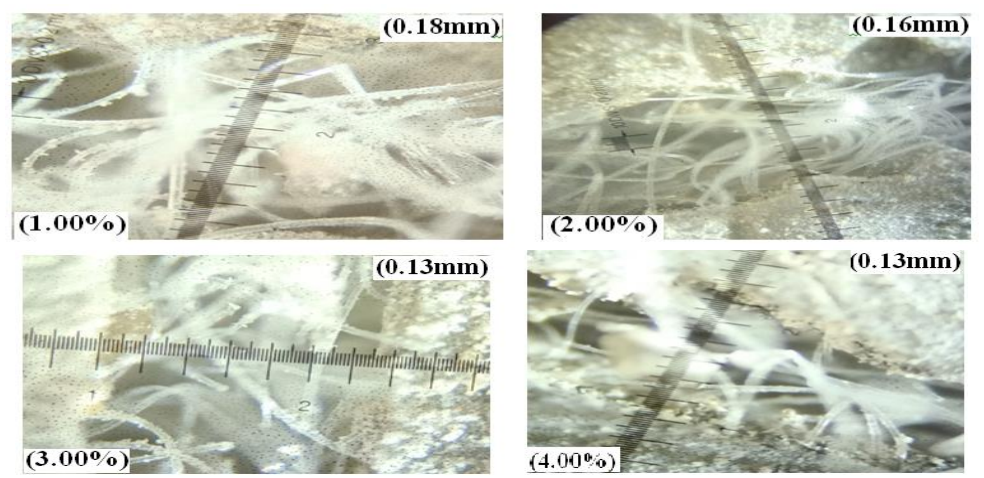

Figure 15- Crack width during the flexural test for Sika Fiber®
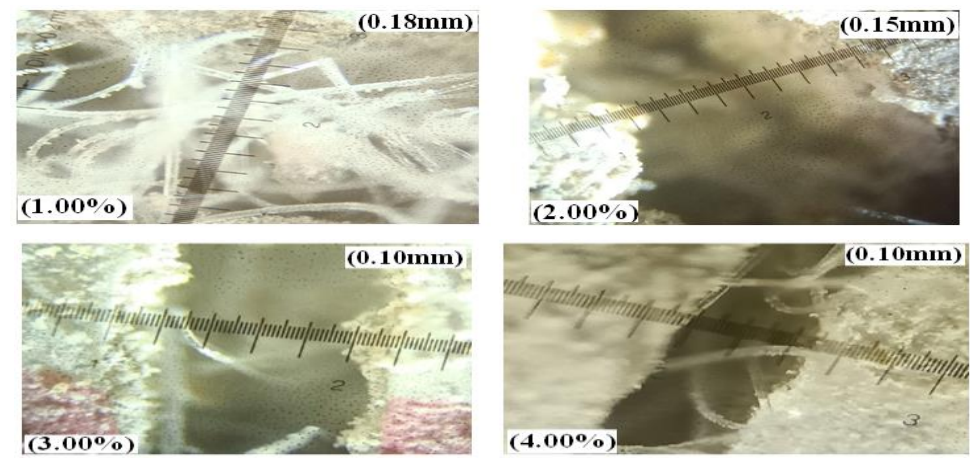

Figure16- Crack width during the flexural test for Fibermish ${ }^{\circledR}$ 300-e3.

\subsection{Tensile Loads}

3.2.1. Effect of using different fiber percentages

The results of the uniaxial test in terms of ultimate strength, ultimate strain and crack spacing are presented in Table (3) and stress-strain curves are displayed in Figure (17) through (19) of the three types of Poly Propylene fibers at different fiber percentages $(1.0,2,0,3,0,4.0 \%)$ involved in this program and control mix. It can be noticed that specimens containing polypropylene fiber with high volume fraction show the better tensile strength among all concretes. Enhancement in tensile strength is expected when the fiber proportion is increased since the plane of failure is well defined (diametric). The higher the number of fibers bridging on the diametrical crack, the higher would be the tensile strength [28]. Figure (17) shows clearly that the tensile strength increases as the content of (TC) fiber increase. The tensile strength of specimens incorporating 1.0, 2.0, 3.0, and $4.0 \%$ of tri concrete fibers (TC) were approximately 4.68, 5.08, 6.36, 6.13 MPa, respectively, while the tensile strength of the control mix was only $2.5 \mathrm{MPa}$. It is obvious that the ultimate strength increases as until reaches $3.0 \%$ fiber content. It is shown that the use of $3.0 \% \mathrm{PP}$ fiber leads to an increase in the tensile strength of about $154.4 \%$ more than control mix. On the other hand, the ultimate strain capacity increases as the fiber content increase. The maximum ultimate strain capacity was 1.67 and $1.66 \%$ for 3.0 and $4.0 \%$ P.P fiber content, respectively. The same trend at figure (18) Sika Fiber ${ }^{\circledR}(\mathrm{SF})$ the ultimate strength for this set of specimens is almost the same range, the ultimate strength of specimen were $4.80,5.16,5.27,5.25 \mathrm{MPa}$ at 1.0, 2.0, 3.0, and $4.0 \% \mathrm{~V}_{f}$ and $2.50 \mathrm{MPa}$ for mix control. It is shown that the use of 3.0 and $4.0 \% \mathrm{~V}_{f}$ fiber leads to an increase in the tensile strength of about $110.8 \%$ more than control mix. While, the maximum ultimate strain capacity was $2.33 \%$ for $2.0 \% \mathrm{~V}_{f}$ fiber content. For figure (19) at Fiber mesh ${ }^{\circledR} 300$ e3 (FM) The ultimate strength of specimens 4.54, 5.13, 5.77, 5.83 and 2.50 $\mathrm{MPa}$ at 1.0, 2.0, 3.0, and $4.0 \% \mathrm{~V}_{f}$ and control mix, respectively. It is shown that the use of $4.0 \% \mathrm{~V}_{f}$ leads to an increase in the tensile strength of about $130.8 \%$ more than control mix. On the other hand, the maximum ultimate strain capacity was $1.67 \%$ for $4.0 \%$ P.P fiber content, respectively. The lowest ultimate strain capacity was $1.0 \%$ for $1.0 \%$ P.P fiber content 


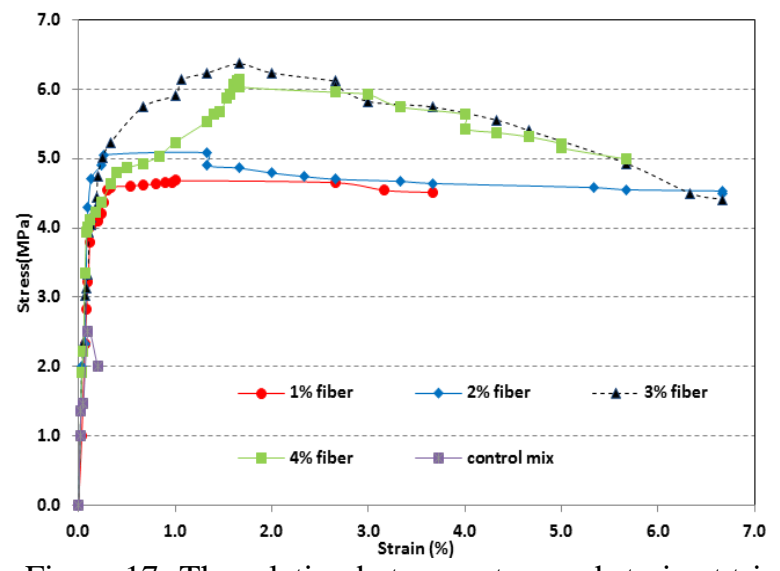

Figure 17- The relation between stres and strain at tri concrete fiber

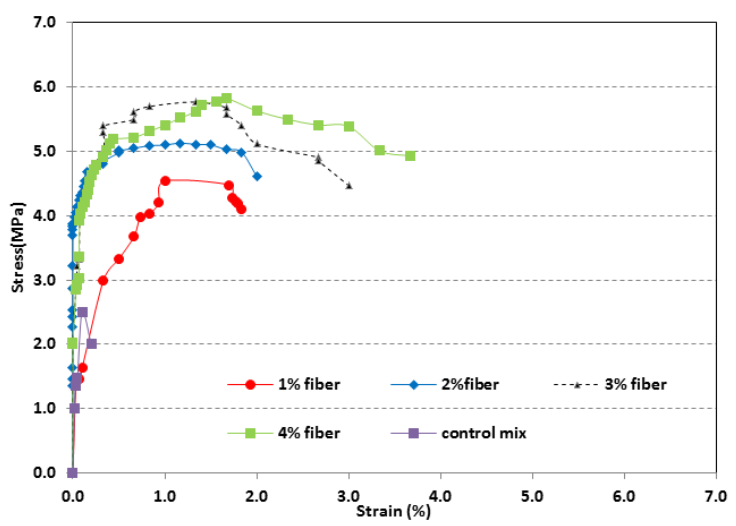

Figure 19- The relation between stress and strain at Fiber mesh ${ }^{\circledR}$ 300-e3

\subsubsection{Effect of using different fiber types}

The tailoring of the composite microstructure is based on the understanding of the mechanical interactions between the fiber, matrix, and interface phases. Under the PDDA, this interaction is quantified by the micromechanics models that provide the link between the composite performance and the micromechanical parameters. Three sets of parameters are involved in the design of PVA-ECC corresponding to the fiber, matrix, and interface phases. The fiber is characterized in terms of volume fraction $\mathrm{V}_{f}$, fiber length $1_{f}$, diameter $\mathrm{d}_{f}$, elastic modulus $\mathrm{E}_{\mathrm{f}}$, and tensile strength $\sigma_{\mathrm{fu}}[29]$. It can be observed that the fiber concrete specimens containing longer PP fiber show the best tensile strength among all concretes. Enhancement in tensile strength is expected with increasing the

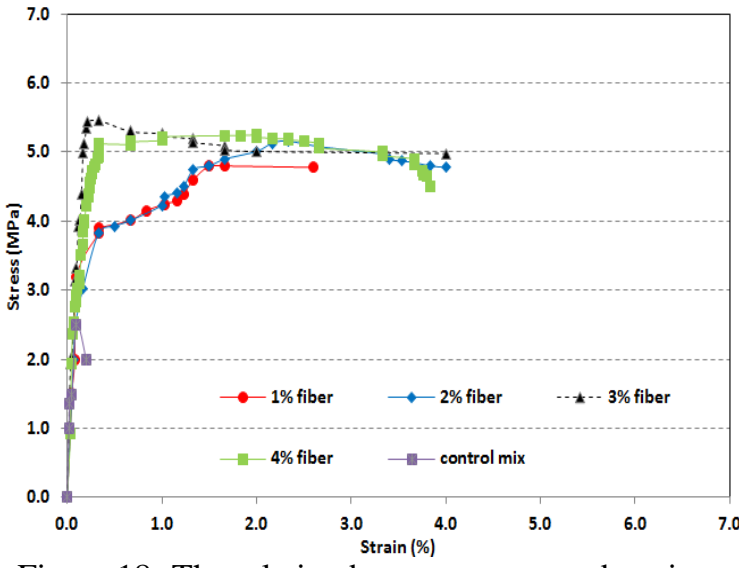

Figure 18- The relation between stress and strain at Sika Fiber® fiber

fiber proportion since the plane of failure. The higher the number of fibers bridging on the crack, the higher would be the tensile strength [26].

From Figsure (20) to (23) illustrate the relation between stress and strain at different volume fraction for three types of fiber and control mix. It can be seen very close in results at the ultimate strength for the set of specimens with same volume fraction more than control mix. Significant improvement in ultimate strength and ultimate strain capacity is observed for the mixes with (SF) and (TC) fiber. This is due to the max aspect ratio, elongation and tensile strength which have it. For example at $1.0 \% \mathrm{~V}_{f}$ Figure (20) (SF) fiber recorded small increase in the ultimate strength and significant increase in the ultimate strain capacity comparing with other fibers and control mix.

The increasing of the ultimate strain for (SF) fiber by 67.0 and $1570 \%$ more than other fibers and control mix. The same trend at $2.0 \% \mathrm{~V}_{f}$ Figure (21) (SF) fiber more than (TC), (FM) and control mix by $75 \%, 99 \%$ and $676.67 \%$, respectively in the ultimate strain. At $3.0 \% \mathrm{~V}_{f}$ Figure (22) (TC) fiber recorded the maximum in ultimate strength and ultimate strain capacity. (TC) fiber was more than that of the mix with (SF), (FM) and control mix by $67 \%, 25.56$ and $1570 \%$, respectively in the ultimate strain. At $4.0 \% \mathrm{~V}_{f}$ Figure (23) (TC) fiber was the maximum in ultimate strength. While, (SF) fiber recorded the maximum in ultimate strength. The increasing of (SF) fiber in ultimate strain by 20.50 and $1900 \%$ more than other fibers and control mix. 


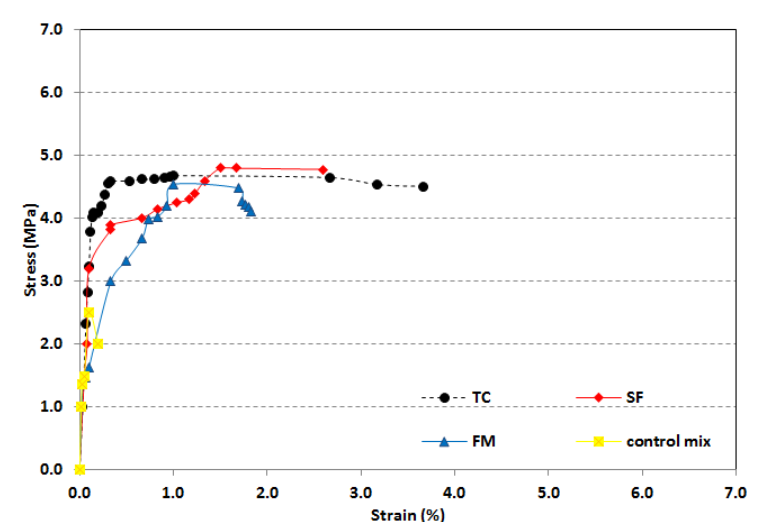

Figure 20- The relation between stress and strain at 1.0

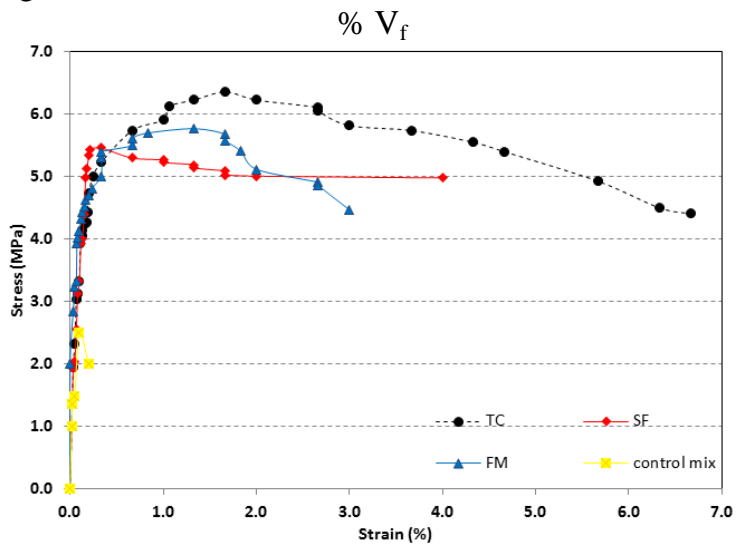

Figure 22-The relation between stress and strain at 3.0 $\% \mathrm{~V}_{\mathrm{f}}$

\subsubsection{Toughness of the Composites}

Toughness is based on the total energy absorbed prior to complete failure. Toughness results of the samples (area under stress-strain curve) are shown in Table 3. The area under the entire stress-strain curve is a measure of the tensile toughness and energy absorption during the tensile test. The numerical integration was carried out using the trapezoidal rule with a relatively small step size for computing the area under the curve[24]. The results showed that the toughness of the composites for the same type of fiber increased as the fiber content increased up to $3.0 \% \mathrm{~V}_{f}$ then decreased at (TC) and (SF). The toughness increased up to $4.0 \% \mathrm{~V}_{f}$ at (FM). By comparing all mixes together (TC) fiber has considerable effect on the toughness of the ECC composite. For example at $3.0 \% \mathrm{~V}_{f}$ the area under curve increased by $101.2 \%$ and $145 \%$ for (TC) comparing to (SF) and (FM) fibers, respectively.

\subsubsection{Effect of fiber types on the crack width of ECC}

The conditions to achieve strain-hardening and multiple cracking of ECC, the $\sigma-\mathrm{W}$ relationship of

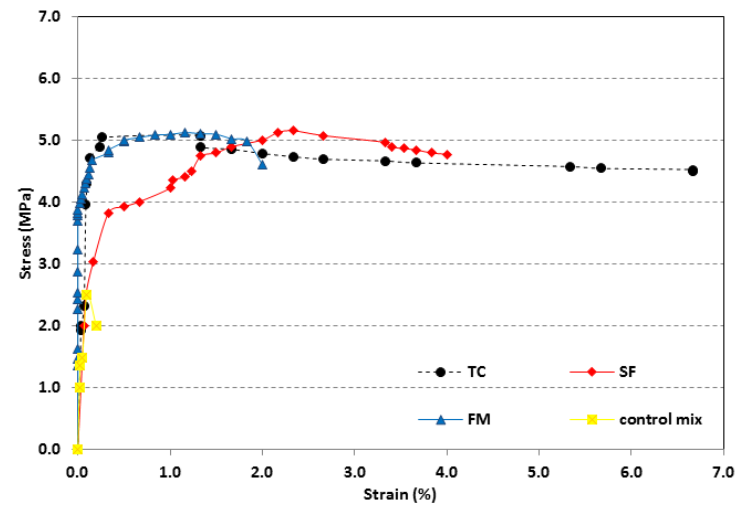

Figure 21- The relation between stress and strain at

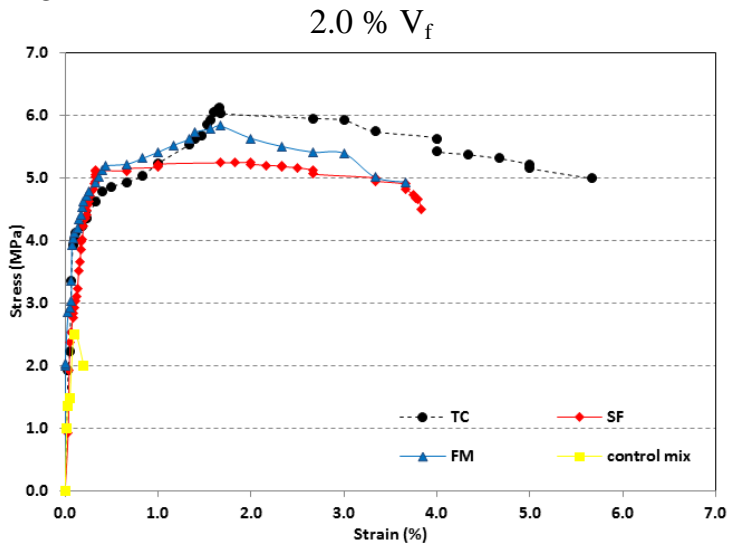

Figure 23- The relation between stress and strain at $4.0 \% \mathrm{~V}_{\mathrm{f}}$

the materials with high fiber content are studied by subtracting the contribution of matrix from the total crack bridging. The complete crack bridging $\left(\sigma_{t}\right)$ in fiber reinforced ementitious composite is composed of matrix bridging $\left(\sigma_{\mathrm{m}}\right)$ and fiber bridging

$$
\left(\sigma_{\mathrm{f}}\right): \sigma_{\mathrm{t}}=\sigma_{\mathrm{m}}+\sigma_{\mathrm{f}} \text {. }
$$

Thus, the fiber bridging can be obtained by:

$$
\sigma_{\mathrm{f}}=\sigma_{\mathrm{t}}-\sigma_{\mathrm{m}} \text {. }
$$

The fiber bridging $\sigma_{\mathrm{f}}$ is proportional to fiber content $\left(\mathrm{V}_{\mathrm{f}}\right)$, and it can be expressed as:

$$
\sigma_{\mathrm{f}}=\mathrm{V}_{\mathrm{f}} \sigma_{\mathrm{f} 1} \text {, }
$$

where $\sigma_{\mathrm{f} 1}$ is the fiber bridging stress of unit fiber volume content.

This means strain-hardening and multiple cracking performances may be obtained by increased with fiber content [30]. This is achieved in Figure (24) shows the relation between the crack width and the different percentages of volume fraction for (TC), (SF) and (FM) to sample under tensile load. From figure, it can be concluded that all the crack widths of the three types of fibers are very close. In addition to, by increasing the fiber content in the mix the crack width decreased. For example, at (TC) and (FM) fiber the minimum crack width at fiber content 3\% as shown in Figures (25) and (27). For (SF) the minimum crack width at fiber content was recorded $2 \%$ as shown in Figure (26) 
Mohamed Saafan, Zeinab Etman, Samar Rokba "Mechanical Properties of Engineered ... "

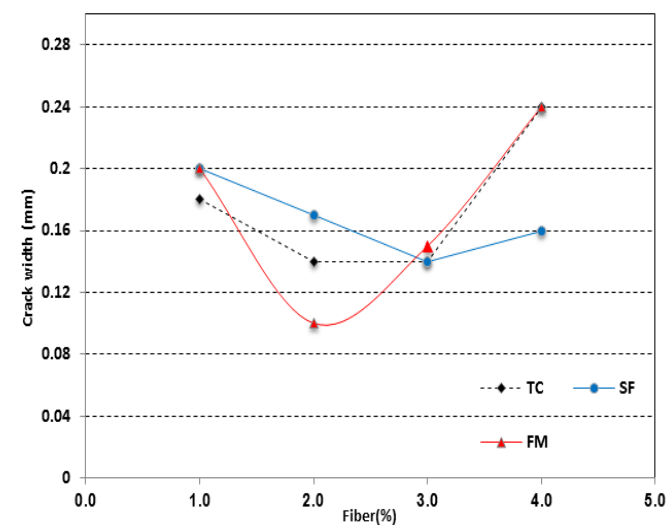

Figure 24- Effect of fiber (\%) on crack width under tensile test
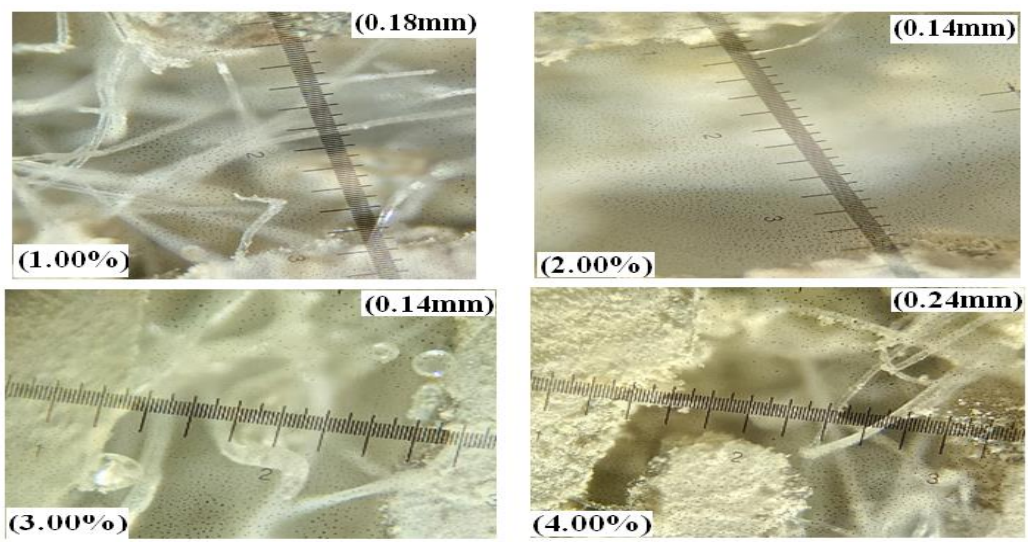

Figure 25- Crack width during the tensile test for (TC) fiber
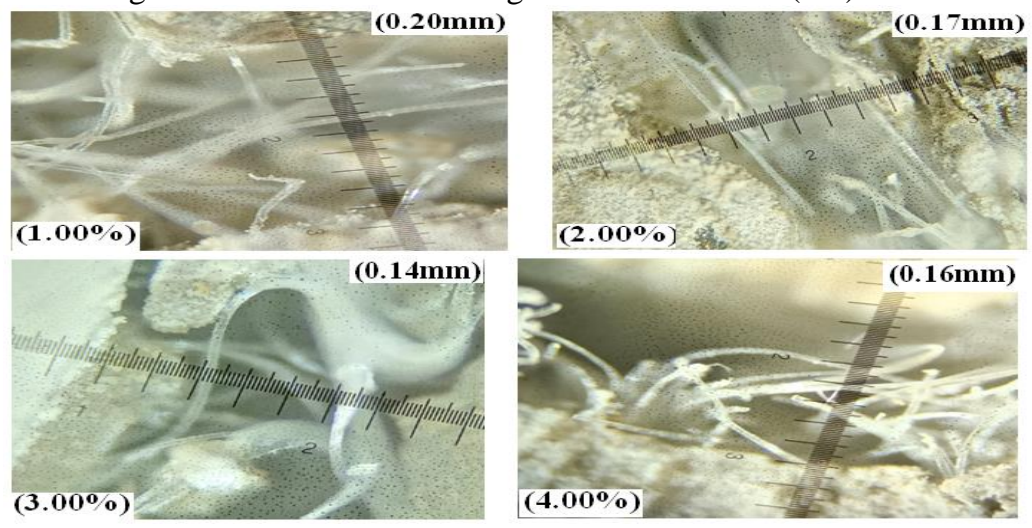

Figure 26- Crack width during the tensile test for (SF)
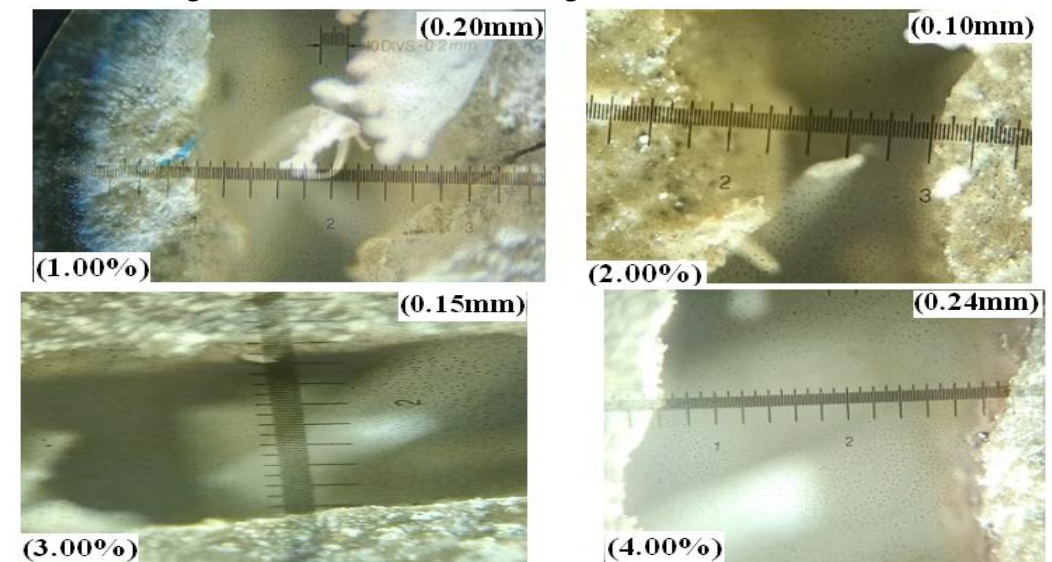

Figure 27- Crack width during the tensile test for (FM) fiber. 


\subsubsection{The Cracking Patterns of ECC}

The cracking pattern reflects unsaturated multiple cracking. It can be seen from Table 3 that the higher strain capacity is accompanied by increase in the number of cracks as shown in Figure (28). This figure shows a comparison between 3 samples of fibers at fiber content $3 \%$. Increasing in the number of cracks at (TC) fiber while adding (SF) and (FM) fibers to the composite mixture adversely affects the number of cracks. Multiple-crack formation gives the composite a higher energy-absorption capability by preventing crack from localization, and increases both the first cracking load and the deformability. In Mix with (SF), most fibers are broken due to the low bond strength of PP. fibers to the cementitious matrix. On the contrary, high modulus is still undamaged across the cracked zone in the composite. These undamaged fibers enhance the deformability and load bearing capacity of composites, especially in the post- cracking zone [28, 31, 32]. After failure of (TC), the high modulus fibers can transfer the load in composite. From the observations it can be concluded that the adhesion mechanism between (TC) and cement matrix is mainly mechanical interlocking. The chemical adhesion and mechanical adhesion in composite containing (TC) arise from the (SF) and (FM) fiber.

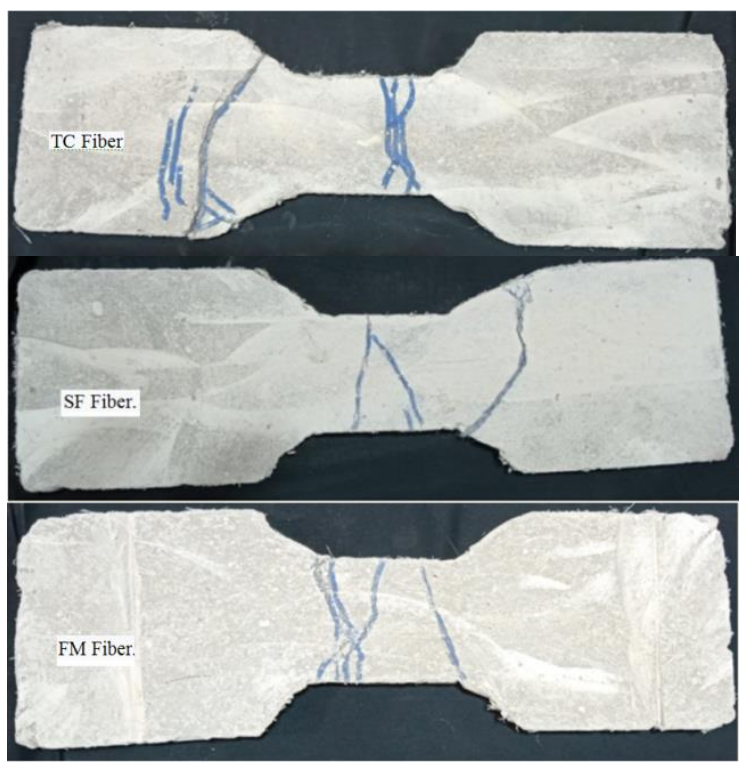

Figure 28-Crack patterns of composites mixes at fiber content $3.0 \%$ under uniaxial tensile test.

\section{Conclusions}

Based on the test results the following conclusions could be drawn:

1- ECC mixes have more deformation average by $1255 \%$ load capacities by $46.24 \%$ compared with control mix, this leads to improve the structure ductility.

2- Minimum crack width, max deformation, and ductility index achieved for tri concrete fiber,
Sika Fiber®, and Fiber mesh®300-e3 at $3.0 \% \mathrm{Vf}$

3- The maximum flexural strength increased by 80, 31.33, and $99.4 \%$ compared to control mix for tri concrete fiber, Sika Fiber®, and Fiber mesh®300-e3 respectively.

4- The minimum crack width was $0.04,0.13$, and $0.1 \mathrm{~mm}$ for tri concrete fiber, Sika Fiber®, and Fiber mesh ${ }^{3} 300-\mathrm{e} 3$ respectively, unlike the control mix that fracture occurred

5- The best type of fibers under flexural strength was tri concrete fiber compared with the other type of fiber; this due to the aspect ratio, tensile strength and elongation of fiber

6- ECC mixes have more strain capacity and tensile strength average by $132 \%$ compared with control mix

7- The ultimate strength and ultimate strain capacity achieved for tri concrete fiber at $3.0 \%$ $\mathrm{V}_{\mathrm{f}}$, and for Sika Fiber®, and Fiber mesh®300$\mathrm{e} 3$ at $4.0 \% \mathrm{~V}_{\mathrm{f}}$

8- The best type of fibers under tensile strength was tri concrete fiber and Sika Fiber®, compared with the other type of fiber; this due to the aspect ratio and tensile strength and elongation of fiber

\section{References}

[[1] K. Kesner and S. Billington "Tension, Compression and Cyclic Testing of Engineered Cementitious Composite Materials" NSF Master Contract Number EEC-9701471, 2004

[[2] A. Alhozaimy, P. Soroushian and F. Mirza "Mechanical properties of polypropylene fiber reinforced concrete and the effects of pozzolanic materials". Cement Concrete Composites" Vol. 18, 1996, pp.85-92.

[[3] S.Mindess and G.Vondran "Properties of concrete reinforced with fibrillated polypropylene fibres under impact loading". Cem. Concr. Res Vol. 18, 1988, pp. 109-115.

[[4] E. Ramya, Ms. S. Nalini, Mrs. S. Sivaranjini and Mr. R.M Saravanakumar "Experimental Investigation of Polypropylene Fiber in Engineered Cementitious Composites" International Journal of Civil and Structural Engineering Research Vol. 2, Issue 2, Month: October 2014 - March 2015, pp: (40-46)

[[5] L. Wee, O. Lian and M. Raizamzamani M. Zain "Mechanical Properties of Engineered Cementitious Composites Using Local Ingredients" Journal of Mech. Engineering Vol. 16, No. 2, 2019, pp. 145-157,

[6] B. Lee, V. Li and Y. Kim "Polypropylene Fiber-Based Strain-Hardening Cementitious Composites" Advances in struct. engineering and mechanics September 8-12 2013

[7] R. Abid, S. Shamkhi, S. Mahdi and Y. Daek "Mechanical Properties of PP-Based 
Engineered Cementitious Composites" International Conference on Advances in Sustainable Engineering Applications. 2018

[8] W. Zhang, Y. Chenglong, M. Fuquan and Z. Huang "Mechanical Properties and Carbonation Durability of Engineered Cementitious Composites Reinforced by Polypropylene and Hydrophilic Polyvinyl Alcohol Fibers" V. 1147 No. 11, 2018,

[9] A. R. Khoso, M. Fahim, Sh. L. Mehgwar and M. A. Akhund "Experimental Analysis on Tensile Behavior of Engineered Cementitious Composite (ECC) using Polypropylene Fiber" Civil Engineering Journal Vol. 4, No. 8, August, 2018

[10] J. Rathod "Effect of Single Fiber Pull Out Test Result on Flexural Performance of ECC" Civil Environ Eng 2014

[11] Egyptian Standarad Specifications 47561/2013, Composition, Specification and Conformity Criteria of Common Cements, Egyptian Organization for Standardization and Quality Control, 2009, 48 pp.

[12] Egyptian Practice Code for Design and Construction of Reinforced Concrete Structures, Ministry of Housing, Utilities \& Urban Development 2018, E.P.C 203-2018, Egypt

[13] Egyptian Standarad Specifications 1109/2008 Aggregates for Concrete, Egyptian Organization for Standardization and Quality control 2008.

[14] ASTM C618, Specification for fly ash and raw calcined natural pozzolan for use as a mineral admixture in Portland cement concrete, Annual Book for ASTM Stand, 4.

[15] ASTM C494/C 494M (2001), Standard Specification for Chemical Admixtures for Concrete, Annual Book of ASTM Standards, 04, 02, p.9.

[16] Tri Concrete Fiber Polypropylene Fiber is manufactured to ASTM C 1116 and C 1339

[17] Sika Fiber® Monofilament Polypropylene Fiber is manufactured to EN ISO 9001 standards and has full British Board Agreement (BBA) approval. Complies with ASTM C-1116-97. Sika Fiber ${ }^{\circledR}$ has been tested as per SCAQMD Rule 1168.

[18] Fiber mesh ${ }^{\circledR}$ 300-e3 fibers are European Standard EN 14889-2-2006 and have been specifically engineered and manufactured in an ISO 9001-2000 certified facility for use as concrete reinforcement

[19] R. Bagherzadeh, H. R. Pakravan, A. H. Sadeghi, M. Latifi and A. A. Merati "An Investigation on Adding Polypropylene Fibers to Reinforce Lightweight Cement Composites (LWC)" Journal of Engineered Fibers and Fabrics. Vol. 7, Issue 4 - (2012)
[20] H. R. Pakravan, M. Jamshidi and M. Latifi "The effect of hybridization and geometry of polypropylene fibers on engineered cementitious composites reinforced by polyvinyl alcohol fibers" Journal of Composite Materials, Vol. 50, No. 8, PP. 1007-102, (2016)

[21] Z. Lin, T. Kanda and V. Li "On Interface Property Characterization and Performance of Fiber Reinforced Cementitious Composites". RILEM Journal of Concr. Science and Engineering, V. 1 (1), pp. 173-184, 1999.

[22] A. Bilotta and G. Lignola "Effects of Defects on Bond Behavior of Fiber Reinforced Cementitious Matrix Materials" mdpi Journal Materials Vol. 164, (2020).

[23] A. Peled and S. Shah "Processing Effects in Cementitious Composites: Extrusion and Casting" Journal of Materials in Civil Engineering · P.P192-199, (2003).

[24] H. R. Pakravan,1 M. Jamshidi, M. Latifi "Performance of Fibers Embedded in a Cementitious Matrix" Journal of App. Polymer Science. V.116, p. 1247-1253 2010.

[25] ACI 544.1R-96, "State-of-the-art report on fiber reinforced concrete, Farmington Hills, Michigan: American Concrete Institute,2002.

[26] B. Jude, Venkatesh, S. Kumar "Effect on Concrete with Engineered Cementitious Composite Using PolyPropylene Fiber"

[27] R. Bagherzadeh, A. H. Sadeghi and M. Latif "Utilizing polypropylene fibers to improve physical and mechanical properties of concrete" Textile Research Journal. Vol. 82, No. 1, pp. 88-96 (2011)

[[28] H. R. Pakravan and M. Jamshidi "Tensile properties of strain-hardening cementitious composites containing polyvinyl-alcohol fibers hybridized with polypropylene fibers" Journal of Cent. South Univ. Vol. 25, pp. 51-59, (2018)

[[29] V. Li, Sh. Wang, and C. Wu "Tensile StrainHardening Behavior of Polyvinyl Alcohol Engineered Cementitious Composite (PVAECC)" Journal of ACI Materials, Vol. 98, No. 6, (2001).

[[30] J. Zhang, X. Ju "Investigation on stress-crack opening relationship of engineered cementitious composites using inverse approach" Journal of Cement and Concrete Research. Vol. 41, P.P 903-912 (2011)

[[31] Sh. Wang \& V. Li "Tailoring of pre-existing flaws in ECC matrix for saturated strain Hardening" research gate, 2011

[32] Z. Zhu, G. Tan, W. Zhang and Chunli Wu "Preliminary Analysis of the Ductility and Crack-Control Ability of Engineered Cementitious Composite with Superfine Sand and Polypropylene Fiber (SSPP-ECC)" mdpi Journal Materials. Vol. 13, 2020. 